\title{
NORM in the extraction industry: Challenges and opportunities
}

\author{
B. Michalik ${ }^{1}$ and R.S. Sidhu ${ }^{2}$ \\ ${ }^{1}$ Central Mining Institute (GIG), Poland \\ e-mail: b.michalik@gig.eu \\ ${ }^{2}$ Institute for Energy Technology (IFE), Norway
}

\begin{abstract}
One of the most serious problems occurring during coal extraction in Upper Silesia in Poland is caused by waters with high salinity which also often contain high concentrations of natural radionuclides, mainly ${ }^{226} \mathrm{Ra}$ and ${ }^{228} \mathrm{Ra}$. Similar phenomenon is also observed in oil and gas industry. On the Norwegian continental shelf, substantial amounts of produced waters containing elevated levels of ${ }^{226} \mathrm{Ra}$ and ${ }^{228} \mathrm{Ra}$ are discharged to the sea. All of these facts outlined elsewhere in the reports serious resulted in contamination of wide areas surrounding mines and other related industries. Research studies conducted so far have provided a lot of data concerning the scale of this phenomenon. But nowadays, all of them should be reconsidered in the light of newest recommendation of the state of-the-art radiation protection. Namely, such waste deposited directly into the environment creates significant risk to the non-human biota that currently must be assessed as well. On the other hand, such scenario of exposure to ionising radiation creates a good opportunity to observe potential effects of low and protracted doses to the living organisms occurring on contaminated areas, especially plants.
\end{abstract}

\section{INTRODUCTION}

Underground waters with enhanced concentration of radium isotopes are very common in nature. They are usually associated with fossil fuels as crude oil and natural gas [1]. It is very well known that the oil and gas extraction industry produces saline waters with enhanced radium concentration. Also, quite often such waters are observed in deep seems of hard coal and investigation done showed that concentration of radium in formation water in Upper Silesian Coal Basin, Poland (USCB) is correlated also with its salinity. Such waters have been found also in German coal mines.

High content of salinity makes these waters not drinkable hence in spite of quite high concentration of radium they do not create a source of direct radiation risk to people. On the other hand radium carried on by these waters is able to precipitate quickly and then settle down. Due to these processes radium can be concentrated in sediments and scales and reach levels significant from radiation protection point of view. External radiation and the possibility of inhalation and accidental intake by ingestion of contaminated substances create a significant risk at such sites. Both humans and the local environment can be endangered by the releases of such substances. Behaviour of contamination and its occurrence depends on the technology applied and local circumstances. In light of state of the art radiation protection a case when environment is endangered by ionising radiation must be evaluated and preventive action should be taken on if necessary. One should expect diverse environmental effects caused by radium in formation waters present in coal mines and oil or gas platforms. Environmental risk assessment process is complex from point of applied methodology as well as relevant legislation. This creates a big challenge for the experts involved in it. On the other hand, the diversity of environmental contamination caused by the effluents containing radium carried on by formation water creates excellent test fields for the investigation of long term effects caused by low doses of radiation. Especially, allowing that different environmental compartments can be contaminated by different branches of mining industry. 


\section{CASES OF CONCERN}

\subsection{Coal mining industry}

The USCB is located in southern part of Poland and up to 65 underground coal mines have been in operation here. Total outflow of waste waters from these mines reaches $700000 \mathrm{~m}^{3} / \mathrm{day}$. Due to their very high salinity (sometimes higher than $200 \mathrm{~g} / \mathrm{l}$ ) they have caused severe damages to the natural environment. Additionally, these waters have often elevated concentrations of radium isotopes ${ }^{226} \mathrm{Ra}$, ${ }^{228} \mathrm{Ra}$ as well as barium and other metals. This phenomenon has been recognized since the 1960's [2].

In USCB, waters with high radium concentration occur mainly in the southern and central part of the coal basin, where coal seams are overlaid by a thick layer of impermeable deposits. First investigation showed that concentration of radium in formation water is correlated with its salinity and it has been found that the behaviour of radium during transportation of radium-bearing brines in the gutters of underground galleries, settling tanks and ponds, pipelines and rivers depends mainly on chemical composition of the brines. Hence two types of radium-bearing waters have been distinguished. Type A waters contain not only radium ions but barium ions as well. Concentration of barium in these waters is at least six orders of magnitude higher than that of radium and reaches $2 \mathrm{~kg} / \mathrm{m}^{3}$. Barium macro amount enables co-precipitation of radium with barium sulphate when radium-bearing water type $\mathrm{A}$ is mixed with water containing sulphate ions, which are very common in nature. In case of radiumbearing type $\mathrm{B}$ waters, where barium ions are not present, concentration of radium ions is too low to enable precipitation of radium sulphate because concentration of $\left[\mathrm{Ra}^{2+}\right]{ }^{*}\left[\mathrm{SO}_{4}^{2-}\right]$ does not exceed the solubility product. Due to differences in their chemical properties, the effect of release of radiumbearing waters type A and type B into the natural environment is completely different. Radium from radium-bearing type $\mathrm{A}$ waters is precipitated out in underground mines and in settling ponds, pipelines and small rivers. Concentration of radium in such precipitates is usually high, reaching $400 \mathrm{kBq} / \mathrm{kg}$ in underground galleries and $270 \mathrm{kBq} / \mathrm{kg}$ on the surface, but the precipitation and sedimentation takes place rather close to the point where radium-bearing waters type A mix with waters containing sulphates. In a distance of a few or several kilometres downstream from the discharge point of mine water the river water is free of radium. On the contrary to the waters type A, radium from radium-bearing waters type B is not precipitated but transported with water to large rivers. Although, concentration of radium in bottom sediments in this case is not very high, contamination of river waters and bottom sediments is observed over a large distance even up to hundred kilometres from the discharge point. Also, properties of sediments created in both cases differ from each other significantly $[4,5]$.

In general presence of radium-bearing formation waters from coal mining industry leads to a few different scenarios where the environmental burden caused, can be significant from radiation protection point of view. Each situation can be described as a combination of following risk scenarios:

- settling ponds with radium baring bottom sediments,

- river bed contaminated by radium baring sediments,

- pipeline below ground or above, sealed by radium bearing scales

In hard coal exploitation process settling ponds were applied to allow mechanical suspensions, carried out by underground brines, to settle. For this purpose some natural lakes or fishing ponds were adapted. Sediments with concentration of both radium isotopes exceeding $200 \mathrm{~Bq} / \mathrm{kg}$ were found inside 25 settling ponds. The total capacity of all these settling ponds reaches 5 millions cube meters. Some of settling ponds have been used for over 25 years and during this period about 200 million $\mathrm{m}^{3}$ of waste waters has been discharged into them. It can have resulted in $100000 \mathrm{~m}^{3}$ (about 150000 tonnes) of total amount of suspension deposited in the pond (fig. 1). Significant increase of dose rates can be observed - up to $42 \mu \mathrm{Gy} / \mathrm{h}$ near the point of inflow of waters into a settling pond. Besides enhancement of natural radioactivity, precipitation and sedimentation processes concentrate heavy metals as well as chlorides and sulphates [6].

The territory of USCB lays in the catchments of Vistula and Oder River. It is densely covered by a grid of small streams and creaks. In the past many of them were adapted as a part of mine dewatering 


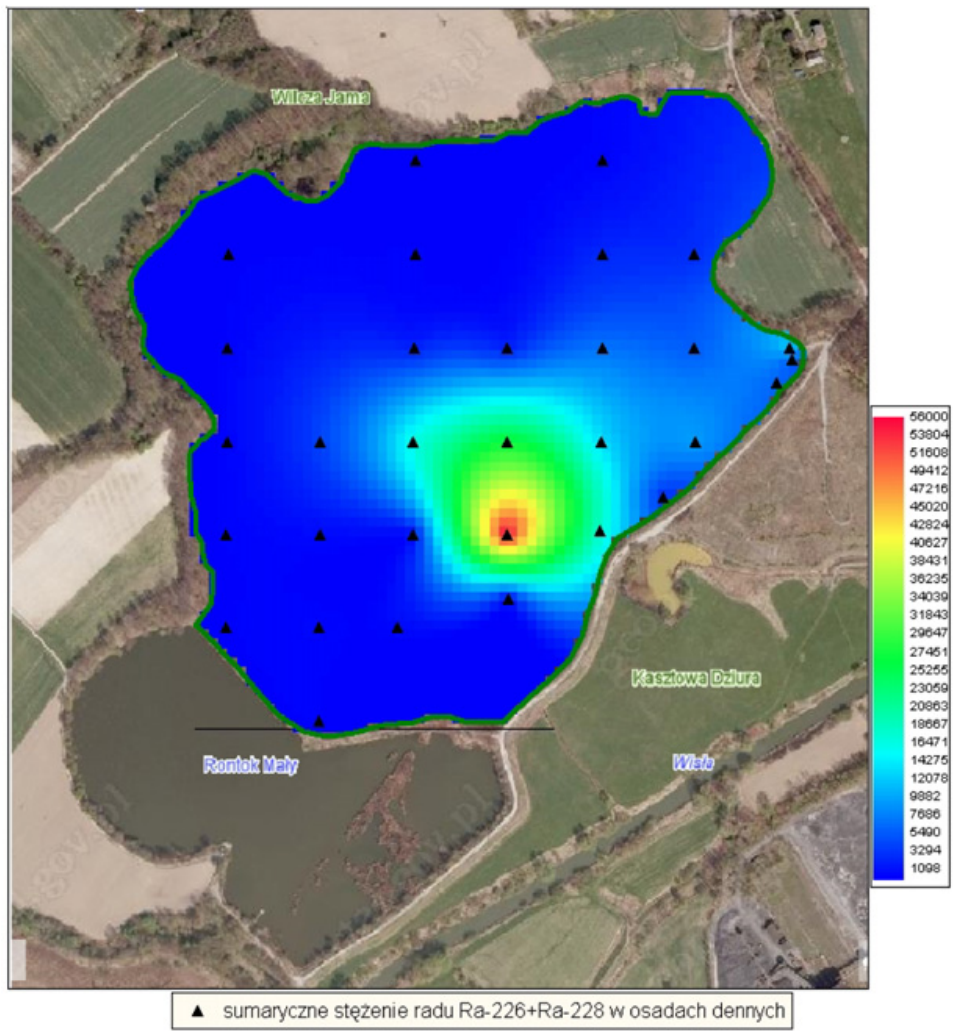

Figure 1. The distribution of radium activity concentration in the bottom sediments.

system. Mine water was discharged to them for many years. Due to the discharge of water with very high concentration of suspended matter, the beds of these streams were covered with contaminated sediments. Probably, in order to keep their capabilities to carry out the water, the beds of these streams were cleaned many times. The bottom sediments were removed and then placed directly on the vicinity of the stream banks. There is no data about the amount of sediments removed and all sites of concern have not been identified. There is some data from the beginning of eighties last century about radium activity concentration in them. The existing data from 1982 and 1986 shows that contamination of soil reached $53 \mathrm{kBq} / \mathrm{kg}$ of ${ }^{226} \mathrm{Ra}$ in some hot spots on the nearest arable lands. The contamination of neighboring lands is still observed. Results of the recent screening measurements done at one stream showed the increment of dose rate up to $6 \mu \mathrm{Sv} / \mathrm{h}$. Activity concentration of ${ }^{226} \mathrm{Ra}$ in soil samples reaches $7 \mathrm{kBq} / \mathrm{kg}$, but activity concentration of ${ }^{228} \mathrm{Ra}$ is quite low and reaches only $75 \mathrm{~Bq} / \mathrm{kg}$. Taking into consideration that in mine water the activity concentration of both radium isotopes is comparable and half life of ${ }^{228} \mathrm{Ra}$ is 5.75 years, it proves that the contamination occurred several decades ago. The range of contaminated land is not exactly assessed but one can expect that it is at least few hundred meters along the stream banks. The area neighboring to the banks of the stream currently is a waste land overgrown by different species of herbaceous plant. In the direct vicinity arable land and inhabited buildings exist.

The third scenario is similar to the one often observed in gas and oil industry. A pipeline, $100 \mathrm{~km}$ long and up to $80 \mathrm{~cm}$ in diameter collects waters from 8 coal mines and finally discharges it directly to the big river Oder. The main purpose of such construction is protection of local small streams against salinity carried by mine waters. By the way this collector system is efficient water cleaner from radium. Diverse water discharged to the pipes are mixed and quickly create scales with very high content of radium. Rough estimation done based on radium balance in waters pumped to the collector and discharged from 
the outflow shows that the collector contains about 20000 tonnes of scales with a total activity of ${ }^{226} \mathrm{Ra}$ and ${ }^{228} \mathrm{Ra}$ equal to $600 \mathrm{GBq}$ and $300 \mathrm{GBq}$ respectively. The dose rate one meter from ground at parts of collector reaches sometimes $11 \mu \mathrm{Gy} / \mathrm{h}$. The collector pipes have been working since the end of seventies last century. Up to now at least two third of the total length of pipes was blocked by scales and left no more than 2 metres below ground level. Contaminated sediments currently are encapsulated in pipes but the process of corrosion is going on and one should expect in future they will contact directly the surrounding environment.

\subsection{Oil and gas industry}

Similar phenomenon as abovementioned is also observed in oil and gas industry. Produced water is a mixture of formation water already present in the reservoir and seawater that may have been pumped into the reservoir to maintain pressure and displace oil. Radium already present in the bedrock is more soluble than the predecessors uranium and thorium, and will therefore be leached from the bedrock by the flooding water and be transported upwards with the produced fluids. As pressure and temperature conditions change, radium present in the produced water may co-precipitate with barium as scale (carbonate or sulphate), but may also remain in solution depending on the chemical conditions, i.e. complexing agents present.

Low specific activity (LSA) scale from oil platforms is composed of ${ }^{226} \mathrm{Ra}$ and ${ }^{228} \mathrm{Ra}$ co-precipitated into host minerals like $\mathrm{BaSO}_{4}, \mathrm{SrSO}_{4}$ and $\mathrm{CaCO}_{3}$. Seawater injection into the reservoirs increases the precipitation of LSA scale. This scale can be deposited far down hole or transported up to topside equipment. The deposits are found on the interior surface of tubes and components, and may lead to complete clogging of equipment. Carbonate scale is mainly formed due to temperature and pressure drop in the upper part of the production system. This scale normally has lower content of radium isotopes than sulphate scale. Sulphate scale is often formed in connection with sea-water injection and deposits are mainly formed in the lower part of the production system (but transport to surface may occur). Third form of scale is lead scale formed during gas production. This scale is probably an underestimated problem in the industry since detection of ${ }^{210} \mathrm{~Pb}$ is problematic and the deposits often are very thin (or even invisible), and the deposits do not interfere with gas production. Radiologically important daughter of ${ }^{210} \mathrm{~Pb},{ }^{210} \mathrm{Po}$, is highly radiotoxic and inhalation of $100 \mathrm{~Bq}$ of ${ }^{210} \mathrm{Po}$ can give a dose of $1 \mathrm{mSv}$. The level of radium and lead isotopes in LSA scale is normally between $0-100 \mathrm{~Bq} / \mathrm{g}$, but deposits with levels of over $10000 \mathrm{~Bq} / \mathrm{g}$ have been encountered.

When LSA scale has been formed in pipes and other equipment it can be mechanically removed, or with use of water jet or "chemical baths". Carbonate scale is easily dissolved in these baths using acid solutions. Sulphate scale dissolution utilize complexing agents as DTPA to dissolve $\mathrm{BaSO}_{4}$ and other sulphates.

Deposits with specific activity above clearance levels given by Norwegian Radiation Protection Authority are treated as radioactive material. Onshore cleaning is done by several companies along the Norwegian coast and radioactive waste from cleaning is temporarily stored at the facilities before it is deposited in an underground repository on the west coast of Norway (Stangeneset repository). Currently the amount of produced/stored/deposited scale in the Norwegian sector amounts to about 400 tonnes. Annual production of LSA scale in the Norwegian sector is about 20 tonnes, but it is expected to increase to $>100$ tonnes/year in the future, partly because of cessation of installations, partly because the production of scale increases with increasing age of the oil fields.

Substantial amount of produced water $\left(143 \mathrm{Mm}^{3}\right.$ in 2004$)$ is discharged to the sea in connection with oil and gas production on the Norwegian Continental Shelf (NCS). The produced water contains elevated levels of ${ }^{226} \mathrm{Ra}$ and ${ }^{228} \mathrm{Ra}$. In 2003 a systematic survey on the levels of ${ }^{226} \mathrm{Ra},{ }^{228} \mathrm{Ra}$ and ${ }^{210} \mathrm{~Pb}$ in produced water from all 41 Norwegian platforms discharging produced water was conducted for 5 consecutive months. The concentration of ${ }^{226} \mathrm{Ra}$ and ${ }^{228} \mathrm{Ra}$ varied between below detection limit $(1 \mathrm{~Bq} / \mathrm{L})$ to $16 \mathrm{~Bq} / \mathrm{L}$ and $21 \mathrm{~Bq} / \mathrm{L}$, respectively. ${ }^{210} \mathrm{~Pb}$ levels were below detection limit. On the basis of these 
results an annual discharge of $440 \mathrm{GBq}^{226} \mathrm{Ra}$ and $380 \mathrm{GBq}^{228} \mathrm{Ra}$ can be calculated. This corresponds to an average concentration of 3.3 and $2.8 \mathrm{~Bq} / \mathrm{L}$ of ${ }^{226} \mathrm{Ra}$ and ${ }^{228} \mathrm{Ra}$, respectively [7].

It is generally assumed that when produced water rich in barium and poor in sulphate is brought into contact with seawater, rich in sulphate, radium will co-precipitate with barium as sulphates. Depending on the size of the particles they will either be transported with the water currents, settle immediately or sorb onto other organic or inorganic particles, and sequentially reach the seafloor. Due to chemical similarities between barium and radium the fate of radium is determined by the speciation of the macro amounts of barium.

In today's oil production, chemicals are added to ease the operation, i.e. scale and corrosion inhibitors, emulsion breakers and surfactants, sulphide removers, etc. These chemicals are usually organic compounds comprising functional groups, which may also interact with cations such as $\mathrm{Ra}^{2+}$ and $\mathrm{Ba}^{2+}$. Thus, radium may exist in compounds more easily accessible for uptake in biota than the inorganic aqueous or food-borne form.

An understanding of how different compounds in produced water affect the mobility, bioavailability, and sedimentation of radium is essential in order to determine the fate and effects of radium discharges. Consequently, sediment-dwelling organisms may be an important group of marine organisms that might be exposed to radionuclides. Once taken up by sediment dwelling invertebrates, the nuclides can be transferred to higher level of the marine food chain (fish), ultimately forming a potential risk for human consumption. In addition to the food-borne route of exposure, water-borne exposure would be expected to form an alternative route by which fish can be contaminated. The relative uptakes from the different exposure routes as well as the effect of chemicals on the bioavailability of radionuclides are of great importance when assessing possible consequences for animal welfare and food safety.

\section{CONCLUSION}

The mining industry has resulted in contamination of wide areas surrounding mines and other related industries. Research studies conducted so far have provided a lot of data concerning the scale of this phenomenon. But nowadays, these studies should be reconsidered in light of the newest recommendation of state of-the-art radiation protection. Namely, such waste deposited directly into the environment creates significant risk to non-human biota that must be assessed as well. This requires a well developed method of environmental risk assessment. On the other hand, such scenario of exposure to ionising radiation creates a good opportunity to observe potential effects of low and protracted doses to living organisms, especially plants. Effects observed in plant cells can be easily broadened to other biota, including human beings. Legacy of NORM industry has provided scientists with interesting test field. Such positive feedback loop created an excellent opportunity to develop methods of adequate assessment of environmental risk derived from radioactive contamination.

\section{Acknowledgements}

The article present results of the Polish-Norwegian joint research project entitled: "Survey of the impact of enhanced natural radioactivity on human and natural environment" supported by a grant from Norway through the Norwegian Financial Mechanism (project No. PNRF-192-AI-1/07 project acronym: "PORANO").

\section{References}

[1] IAOGP (2008): International Association of Oil and Gas Producers. Guidelines for the management of Naturally Occurring Radioactive Material (NORM) in the Oil \& Gas Industry Report No. 412.

[2] Michalik B. (2004): Environmental pollution caused by natural radioactivity occurring in mining industry - the scale of the problem. Sustainable Post-Mining Land Management, Edited by: 
Euromines, CBPM CUPRUM Wrocław and Mineral and Energy Economy Research Institute Polish Academy of Science, Kraków - Wrocław, p. 145-154.

[3] Chałupnik S., Michalik B., Wysocka M., Skubacz K., Mielnikow A. (2001): Contamination of settling ponds and rivers as a result of discharge of radium-bearing waters from Polish coal mines. Journal of Environmental Radioactivity 54, pp. 85-98.

[4] Karsten L., Michalik B., Wiegand J. (2007): Availability of radium isotopes and heavy metals from scales and tailings of Polish hard coal mining. Journal of Environmental Radioactivity 94, s. 137-150.

[5] Godoy, José Marcus; Petinatti da Cruz, Rosana. (2003): ${ }^{226} \mathrm{Ra}$ and ${ }^{228} \mathrm{Ra}$ in scale and sludge samples and their correlation with the chemical composition Journal of Environmental Radioactivity Volume: 70, Issue: 3, pp. 199-206

[6] Michalik B., Wysocka M., Chałupnik S., Skubacz K., Mielnikow A., Trząski L. (2005): Contamination Caused by Radium Discharged with Mine Effluents into Inland Waters, Radioprotection Vol. 40, Suppl. 1 p. 503-509.

[7] Gäfvert, T. and Færevik, I. (2005). Natural Radioactivity in Produced Water from the Norwegian Oil and Gas Industry in 2003. NRPA Report 2005:2. 